Original Research Paper

\title{
Proposed Self-Regulation Model for Collaborative E-Learning Systems in Kenyan Public Universities
}

\author{
Grace Leah Akinyi and Robert Oboko \\ School of Computing and Informatics, University of Nairobi, Nairobi, Kenya
}

Article history

Received: 26-08-2019

Revised: 31-12-2019

Accepted: 10-01-2020

Corresponding Author: Grace Leah Akinyi

School of Computing and Informatics, University of Nairobi, Nairobi, Kenya Email: ograceleah@gmail.com.

\begin{abstract}
Integration of technology in learning such as Electronic-learning has become an indispensable segment of higher education in Sub-Saharan Africa. This has opened up opportunities that improve teaching and learning. There is need for intervening in e-learning environments towards developing Self-regulated learning support, which can lead to improvement in performance and learner retention. SRL provides students with capability to acquire and update complex and systemic concepts and make judgements about their progress as they do so. Lack of ability to self-regulate is a major reason for dropout rates and poor performance in E-learning courses, due in part to students not recognizing the effort and organization required to succeed in online courses and the difficulty for instructors to monitor student progress. This study was carried out in order to develop an SRL model for collaborative e-learning based on SRL theories to determine the SRL strategies to model. The study proposes an SRL model based on Social Cognitive Theory of SRL as an intervention for reducing drop-out rates and improving performance of elearning environments in Kenyan Public Universities.
\end{abstract}

Keywords: Self-Regulated Learning, Peer Learning, Collaborative eLearning, Intelligent Educational Systems, Student Performance and Retention

\section{Introduction}

Most learners today need convenience in their learning processes. Integration of technology in learning has opened up new opportunities that improve teaching and learning such as in Electronic-learning (E-learning). An E-learning platform delivers flexibility in learning and refers to internet based learning processes, which use internet technology to design, implement, manage, support and extend learning (Siddiqui and Masud, 2012; Sanja, 2015). An e-learning system allows access to education to those who are unable to physically be present in the traditional classroom based learning (Ssekakubo et al., 2011) as well as complementing it. In contrast to traditional learning where student-teacher interaction occurs face-to-face in a classroom (Artino and Jones, 2012), e-learning relies on the use of asynchronistic and synchronistic interaction within a virtual environment (Hadullo et al., 2018). Synchronous access involves real-time learning using live chats or online video-conferencing, while asynchronous access involves any offline materials that the learner uses such as e-mails and downloaded notes from the LMS. The success in an e-learning environment relies on a student's ability to autonomously and actively engage in the learning process (Wang et al., 2013), besides providing adequate infrastructure and learning support.

There has been a steady increase in e-learning enrollment for undergraduate students in Higher Education Institutions (HEIs) in Africa (Wandler and Imbriale, 2017) due to an increase in internet access in the past decade (Greenland and Moore, 2014). In contrast, Higher e-learning institutions in sub-Saharan Africa have experienced high drop-out rates due to factors such as (i) Lack of direct interaction between instructors and learners, (ii) the difficulty for instructors to monitor student progress (Lodge et al., 2018), hence e-learners may experience a sense of isolation, (iii) lack of ability to self-regulate (Lee and Choi, 2011), which may in part be due to students not recognizing the effort and organization required to succeed in e-learning courses and (iv) limited self-regulatory skills (Cho and Shen, 2013). Instructors need to carefully consider and purposefully plan and facilitate student learning in support of the development of self-regulation in an e- 
learning environment (Greene et al., 2011; Wong et al., 2019). In Kenya, e-Learning students have cited lack of support from instructors and peers (Maina et al., 2017), hence need to strengthen their own ability and skills in self-regulation. Self-Regulated Learning (SRL) can be defined as self-generated thoughts, feelings and actions that are planned and cyclically adapted to the attainment of personal goals (Zimmerman, 2000). SRL refers to a learner's capability of active participation in the learning process by using different learning strategies.

E-learning students are required to be more independent, as the nature of online settings promotes self-directed learning and need to have self-generated ability to control, manage and plan their learning actions (Lock et al., 2017), as opposed to the traditional classroom peers. E-learning collaborative platforms provide self-regulated learning capabilities which empower students and instructors, who are physically isolated from each other (Meyer and Turner, 2002) through flipped or inverted classrooms. There is need to explore the collaborative element in e-learning which has pedagogical advantages such as development of critical thinking skills, co-creation of knowledge and meaning, reflection and transformative learning (Maina et al., 2017).

Furthermore, e-learners also need to develop multiple skills to be able to establish goals, monitor their progress towards those goals, correct the performance if needed and evaluate the outcome while extracting conclusions for the next performance. These can be achieved through the use of SRL strategies

The study focuses on how SRL strategies can be used to improve academic performance in e-learning in Kenyan Education settings. SRL strategies include: the cognitive, metacognitive, behavioral, motivational and emotional or affective aspects of learning. Through the use of SRL, learners can take responsibility for their learning by setting their own goals, applying the various SRL strategies to achieve the goals, monitoring their study and evaluating their performance (Zimmerman, 2000). SRL is part of social cognitive theories and has been widely used to explain the behavior of humans. Its unique contribution has been on how it emphasizes the triadic interaction between the person, behavior and the environment, which accounts for personal factors like cognition, affection, how individuals are capable of manipulating, reacting to, influencing and exclusively depending on their environment (Bembenutty et al., 2016).

\section{Problem Statement}

Despite high enrolment rates in e-learning courses in public universities in Kenya majority of learners do not successfully complete the courses. Recent studies show that although over $90 \%$ of students enroll into elearning courses, only about $35 \%$ of them successfully graduate (Maina et al., 2017; Kashorda and Waema, 2014; Makokha and Mutisya, 2016). E-learning students drop out for a variety of reasons; (i) lack of online support as a result of the learner studying in isolation, (ii) poor course interactivity, (iii) lack of motivation from instructors and peers and (iv) poor internet connectivity (Wong et al., 2019; Oboko, 2012; Tarus et al., 2015).

\section{Research Objectives}

The study aims to attain the following objectives:

1. To assess differences in overall familiarity and frequency of use of collaboration tools and selfregulated learning strategies in Kenyan e-learning systems

2. To determine the relationships between SRL strategies and course performance in undergraduate e-learning students in Kenya

3. To integrate an SRL model based on other models that is suitable for the Kenyan e-learning environment

\section{Research Questions}

The study sought to answer the following research questions:

1. How can the differences in overall frequencies of use of and familiarity with collaboration tools and SRL strategies in Kenyan e-learning systems be assessed?

2. What are the relationships between SRL strategies and course performance in undergraduate e-learning students in Kenya?

3. How can an SRL model that fits the Kenyan education context be integrated from other SRL models?

\section{Technology Description}

\section{E-Learning Systems}

E-learning is a modality of learning that uses digital media, information and communication technologies to offer education to learners who cannot access faceto-face learning (Wentling et al., 2000). Most elearning systems use Learning Management Systems which provide a place to teach and learn without depending on the time and space boundaries. Most Public Universities in Kenya use an open source software platform called Moodle. 


\section{Status of E-Learning Adoption in Kenya}

In Kenya, most public universities have introduced elearning programs which are set-up on their eCampus portals to tap majority of students who lack time to attend physical lectures and instead prefer to study online. Recent studies in Kenya have shown that elearning is the preferred mode of learning for students and mode of teaching for lecturers (Maina et al., 2017; Makokha and Mutisya, 2016). However, most learners have termed their e-learning modules as non-interactive and lack of supports for cognitive and metacognitive learning for e-learners who tend to learn on their own. This calls for introduction of self-regulatory skills to the learners.

The findings also indicate that most learners have low interaction with e-learning tools and technologies, due to majority of them lacking SRL support strategies (Makokha and Mutisya, 2016). To address the ever increasing demand for e-learning programs in Kenya, Maseno University (MSU) runs an eCampus program. According to MSU website, the program offers 18 programmes through fully-online and blended elearning, 6 of these being undergraduate programmes with about 60 course units per program in total. Consequently, other public universities in Kenya operate in the same way with their e-learning portals designed for both fully online and blended learning. For this study the focus is on blended learners.

To give further insight into the problems stated, a pre-study was conducted between October and November 2019 through interviews on Maseno University e-learning students. An interview theme was prepared with just one broad goal seeking to find out the problems that e-learning students face in their respective universities. Data was recorded from the interviews and then transcribed to obtain categories of the issues affecting e-learning students.

The findings of the pre-study were placed into three categories: Lack of instructor support, lack of selfregulatory skills and poor or lack of group participation. Firstly, regarding lack of support, the learners reported that the instructors abandoned them and never supported them adequately during their studies. Secondly, regarding the problem of lack or no use of SRL skills, the learners reported that their interaction with the collaborative tools was low while others reported a lack of understanding of the tools and strategies altogether.

Lastly, the other problem facing e-learners in Kenya emerged from a reported lack of participation among group members, peers and individuals, whereby inactive e-learners would let active peers do assignments for them, then later pose as if they had equally participated in the tasks. Others complained of workload not shared equally among the students in an online collaborative learning group, prompting the learners to seek for unethical means for doing their assignments by paying experts or consultants to carry out class assignments for them, only to submit as their original work.

The findings from this pre-study confirmed most problems that exist from research (Maina et al., 2017; Makokha and Mutisya, 2016), but also contradicted the numerous studies from other regions which mostly address the benefits of e-learning.

\section{Collaborative E-Learning}

Online collaboration is recognized as an educational approach that is based on the constructivist view of learning requiring learners and instructors to work together when solving problems, completing tasks, or creating products (Maina et al., 2017). Its major benefit is creating online learning communities rich in collaborative learning tasks. In the past, collaborative learning has been restricted to the classroom environment because of the logistical difficulties in distance learning environment. However, the introduction of internet technologies and other online tools offers new opportunities for student collaboration in an online environment as well as posing new challenges for teachers supporting group work (Maina et al., 2017).

\section{Social Cognitive Theory}

Information Systems theories are used to guide the development of systems used within Information Systems domain. One such theory used to guide the development of e-learning systems is the Social cognitive theory. The theory of student self-regulated learning was proposed based on social cognitive theory (Bandura, 1986), where a distinction is made among personal, environmental and behavioral determinants of self-regulated learning. Self-regulated learning is not determined merely by personal processes but it is assumed to be influenced by environmental and behavioral events in a reciprocal manner. SRL occurs to the degree that a student can use personal processes to strategically regulate behavior and the immediate learning environment (Zimmerman, 2000).

An e-learner's personal capacity to self-regulate is assumed to depend on learning and development. Therefore, more experienced e-learners are believed to be better able to self-regulate themselves during learning than inexperienced ones. The experienced e-learners can make use of appropriate self-regulation strategies in constructing and selecting courses of actions which improve their academic performance.

The social cognitive theory assumes that self-efficacy is a crucial component of self-regulated learning. Efficacy beliefs will influence how students feel, think, motivate themselves and behave (Bandura, 1986). Research shows that students with greater sense of perceived self-efficacy display more of the behavioral and environmental determinants of SRL and are more 
likely to set higher goals for themselves having a firmer commitment to them. This is a characteristic of learners who are intrinsically motivated and notably high academic achievers. Learners who are extrinsically motivated and a motivated are more likely to be less self-determined and hence, their use of SRL strategies will be limited compared to the intrinsically motivated learners (Makokha and Mutisya, 2016).

\section{Group Formation}

The approach used in group formation can determine which e-learner joins a group and who is the leader of the group. Group formation refers to a process of identifying e-learners then assigning them to a specific group so that they belong to one group when doing a group task (Maina et al., 2017). For instance, some groups may be homogenous, while others may be heterogeneous. Thus, the motivation of the learners and the way the collaborative learning processes work can impact on the learners' comfort and hence their continued learning using the e-learning platform (i.e., elearner retention). Therefore, the method of group formation can affect e-learner performance.

In homogeneous group formation an e-learner joins a group with other members who have similar characteristics such as course interests, work schedules and residential proximity. In heterogeneous group formation an e-learner joins a group with other members who have different or diverse characteristics such as academic achievement, learning styles, personality profiles and demographic information which could include: Age, gender, racial and ethnic or cultural background. Heterogeneous groups are always preferred because of the belief that they produce constructive controversy (Maina et al., 2017).

There are different methods for group formation: Firstly, random selection method, which is highly utilized by instructors due to its perceived ease of implementation and fair distribution. It gives a learner equal chance to be a member of any group, hence both social and academic heterogeneity can be achieved. However, it can lead to lack of diversity in skills within the group due to randomness in the placement of learners into groups (Maina et al., 2017).

Secondly, self-selection methods improve students' performance in group work than randomly assigned groups (Maina et al., 2017). The method allows students to: Communicate better, have positive attitude towards group work and feel more excited to work together, feel more comfortable to consult one another in their group for help, take more pride in their work and are able to resolve conflicts better.

Thirdly, the use of intelligent systems to do group formation in online collaborative learning environments has also been reported in recent research (Maina et al., 2017). Although computer based random selection methods have been preferred in large classes, intelligent techniques are better because they do incorporate learner's characteristics like learning style, learner's profile and context and contextual information. They also change the group allocation. The method also provides for ability to change the group member composition in real time, which enables the leveling up of learning results. Some of the intelligent techniques have applied the use of machine learning techniques like Instance-based Learning and Bayesian network to predict an appropriate group for the learner, based on the contextual information.

\section{SRL Strategies}

Self-Regulated Learning (SRL) strategies enable a self-regulated learner to actively engage self-regulated processes (Perry and Rahim, 2011). In order to be successful, e-learners must rely on their individual abilities to direct their learning, by employing SRL Strategies (Wandler and Imbriale, 2017; Muuro et al., 2016). All students are self-regulated learners to some degree, but not all students are necessarily strong selfregulated learners (Zimmerman and Schunk, 2011). Self-regulated learners utilize different Strategies.

Categories of collaborative SRL Strategies include (Alvi et al., 2016).

\section{Metacognitive Strategies}

Metacognitive strategies refer to the awareness to monitor, plan and regulate learning (Alvi et al., 2016). They are used to enhance behavioral functioning. There are various types of metacognitive strategies.

Metacognition refers to the capability of learners to understand and monitor their cognitive processes and thinking. This is the awareness and control of mental thoughts. Researchers have examined the effect of metacognitive strategies on online academic outcomes; some studies found a significant positive relationship with e-learning (Alvi et al., 2016; Puzziferro, 2008) while others found a non-significant relationship (Johnson et al., 2016; Klingsieck and Fries, 2012).

Time management is the ability to plan study time and tasks (Effeney et al., 2013). Studies that have reviewed the role of time management or study management in e-learning success, include those that found a significant positive relationship (ChanLin, 2012; Michinov et al., 2011) and those that did not find a significant relationship (Klingsieck and Fries, 2012).

Effort regulation refers to the capacity to persist when confronted with academic challenges (Richardson et al., 
2012). Some studies that examined the relationship between effort regulation and academic grades in elearning, found a significant positive relationship (Puzziferro, 2008; Cho and Shen, 2013), while others did not find any significant relationship (ChanLin, 2012).

Organization relates to one's ability to highlight main points during learning (Effeney et al., 2013). Some studies explored the effect of organization on academic performance; one study found a weak positive significant relationship (Puzziferro, 2008) and others did not find a significant relationship (Klingsieck and Fries, 2012).

\section{Cognitive Strategies}

Cognitive strategies help learners acquire knowledge at a surface level by retaining information. They are used by students to optimize personal regulation. There are various types of cognitive strategies.

Rehearsal refers to learning by repetition (Effeney et al., 2013). Recent studies have explored the relationship between rehearsal and e-learning academic achievement; one study found a weak positive significant relationship (Puzziferro, 2008), whereas other studies did not find a significant relationship (Klingsieck and Fries, 2012; Wang and $\mathrm{Wu}, 2008$ ).

Elaboration is the ability to link new and existing information with an aim of remembering new contents (Richardson et al., 2012). Some studies examined the effect of elaboration in e-learning academic achievement; one found a weak positive significant relationship (Puzziferro, 2008), whereas others found an insignificant relationship (Klingsieck and Fries, 2012; Wang and $\mathrm{Wu}, 2008$ ).

Critical thinking refers to the ability to carefully examine learning material (Richardson et al., 2012). Some studies reviewed the effect of critical thinking on academic performance and found a weak positive significant relationship (Puzziferro, 2008), while others found an insignificant relationship (Wang and $\mathrm{Wu}, 2008$ ).

\section{Motivational Strategies}

Motivational orientations include performance and learning goals which influence learners' engagement in SRL (Dweck and Master, 2008). Learners provide different reasons for their goals. For example, obtaining a degree or job, social recognition, or personal interests. For learners to develop interest in learning, they mostly relate to internal sources of motivation, such as relating learning to daily life, strategic actions, moving from simple to complex and other intrinsic interests. Motivation can also come from external sources such as the regulating environment and test scores provided (Bandura, 1986).

\section{Resource Management Strategies}

Resource management strategies require learners to manipulate available resources and maximize learning environments around them such as their peers or instructors (Puzziferro, 2008). They are intended to optimize the student's immediate learning environment. E-learning students usually consult different resources such as journals, libraries, books and the net. They seek assistance and sometimes work in groups to maximize learning and performance during different occasions such as while doing assignments or when preparing for exams at the end of the semester. Examples of resource management strategies include:

Peer learning, which involves collaborating with other learners in order to aid one's learning (Effeney et al., 2013), such as when an e-learning student uses an online discussion forum to meet up with his/her classmates to discuss an assignment. Some studies have examined the effect of peer learning on academic achievement, with most of them finding a significant positive relationship (ChanLin, 2012; Johnson et al., 2016; Michinov et al., 2011; Puzziferro, 2008).

Help seeking relates to obtaining assistance from instructors or better placed peers, with the aim of overcoming academic challenges (Richardson et al., 2012), such as when an e-learning student emails their instructor seeking clarification from some learning tutorial.

Generally, most of the strategies have been integrated into e-learning, but the studies on this are not many. This is an area that needs further exploration.

\section{Self-Regulated Learning Models}

A number of Self-Regulated Learning (SRL) models have been adopted in the context of e-learning. Some of these are Zimmerman's Model, Winne and Hadwin's Model and Hadwin and group's Model.

\section{Zimmerman's Cyclical Model (2001)}

Zimmerman's cyclical SRL model (Fig. 1) has served as a theoretical foundation for studies which evaluate learners' self-regulatory processes within naturalistic, non-academic and academic settings (Panadero, 2017). This triadic model highlights three phases of self-regulation: (i) Forethought phase involves task analysis and self-motivation, where learners set their learning goals. (ii) Performance Control Phase emphasizes self-monitoring of performance by the learners (iii) Self-Reflection Phase involves selfjudgment and self-reaction with a highlight of 
participation in self-reflection after monitoring one's task performance.

\section{Winne and Hadwin's Model}

Winne and Hadwin's model (Fig. 2) of SRL identifies SRL learners as active participants who manage their own learning through monitoring and using cognitive strategies while declaring the goal driven nature of SRL and the effects of self-regulatory actions on motivation (Panadero, 2017). The model has been used widely in studies implementing computer supported learning settings (Panadero and Sanna, 2015). In this model, studying is driven across four linked open and recursive phases which are comprehended in a feedback loop (Panadero, 2017).

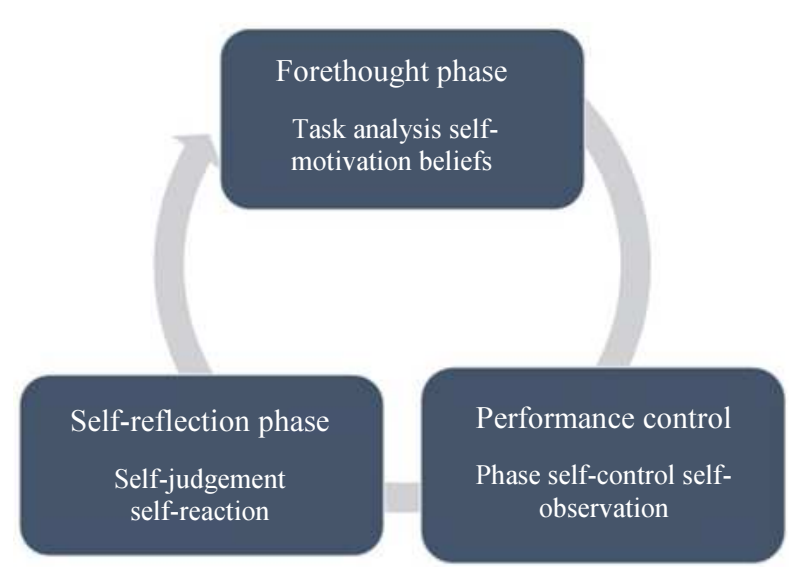

Fig. 1: Cyclical model of the self-regulated learning process (adapted from Zimmerman, 2000)

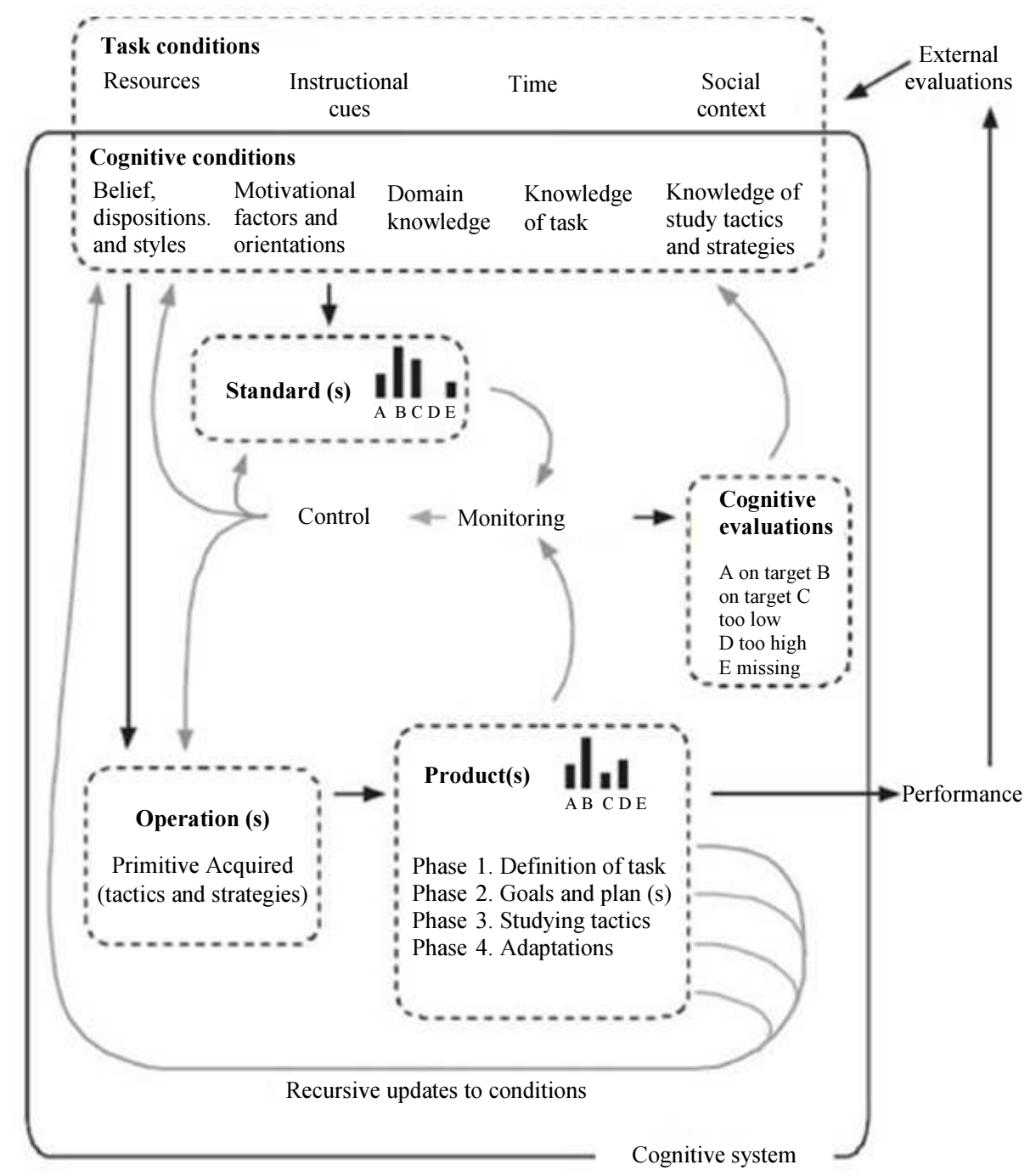

Fig. 2: Winne and Hadwin's SRL model. Adapted from Winne and Hadwin (1998) 


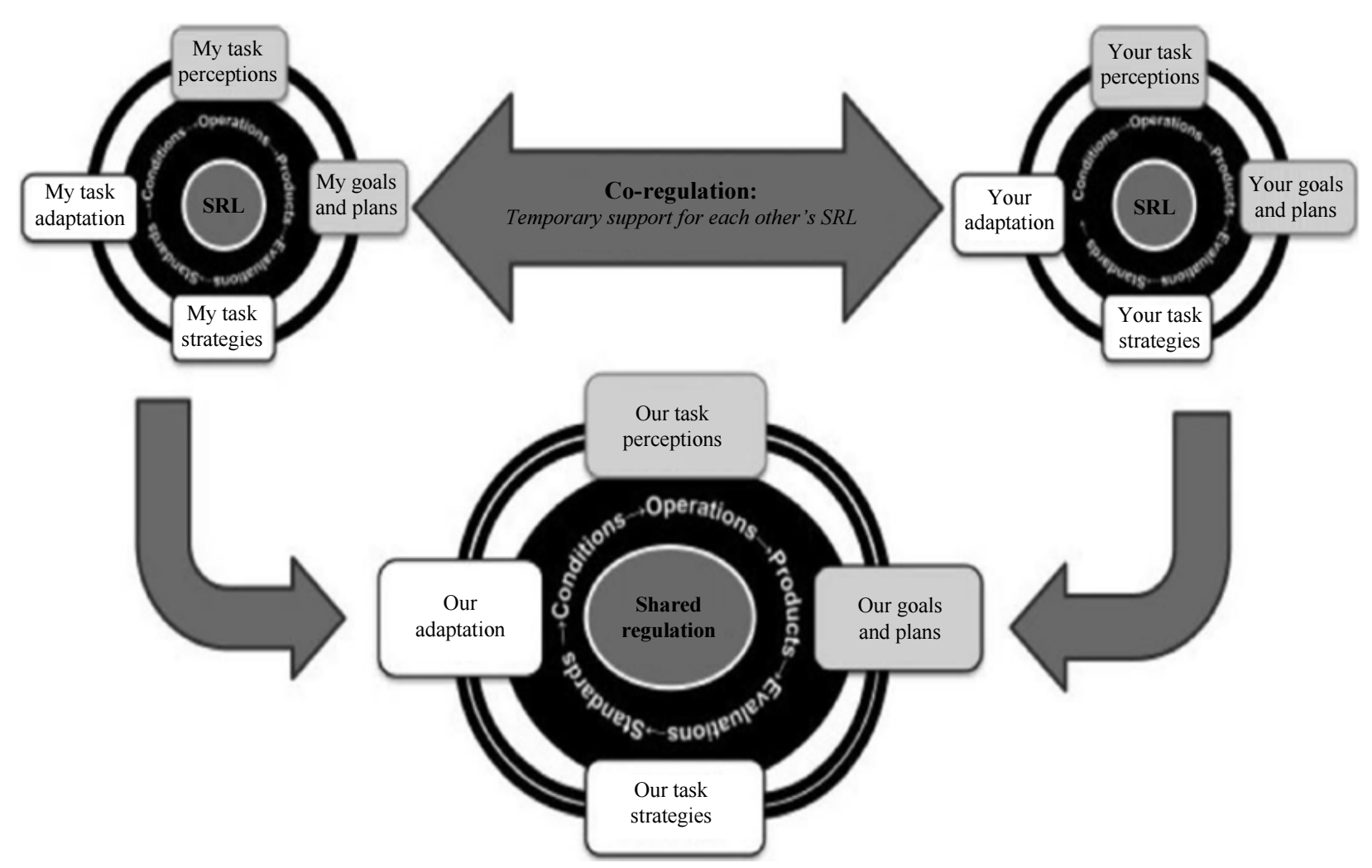

Fig. 3: Socially Shared Regulated Learning model (SSRL) 1. Adapted from Järvelä and Hadwin (2013)

\section{Socially Shared Regulated Learning Model}

Also known as Järvelä and Hadwin's Model (2013), the Socially Shared Regulated Learning (SSRL) Model (Fig. 3) has its metacognitive foundation based on Winne and Hadwin's (1998) Model. The model also clarifies regulation in social and interactive learning environments using computer-supported collaborative learning and ICT environments (Panadero, 2017; Järvelä et al., 2016). There is a 2011 version of the SSRL model by the same authors. The major difference between the two is that the role of external entities in the collaborative learning process is recognized in the 2013 model. In addition, the steps involved in SRL are defined more clearly in the later model.

The concept of socially shared regulation of learning (SSRL) occurs when groups of e-learners regulate together as a collective, such as when they construct shared task strategies or shared goals or shared task perceptions. When groups co-construct plans or align monitoring perceptions to establish a shared evaluation of progress, they are engaged in shared regulation. SSRL involves interdependent or collectively shared regulatory processes, beliefs and knowledge (e.g., strategies, monitoring, evaluation, goal setting, motivation, metacognitive decision making) orchestrated in the service of a co-constructed or shared outcome (Panadero and Järvelä, 2015).

\section{Definitions of Conceptual Elements}

One of the independent variables in this study, namely Group Formation will be derived from group formation techniques (Fig. 4). Three different group formation techniques to be studied include: random assignment, Grade Point Average (GPA) and intelligent grouping. Group Formation independent variable refers to the technique used to place collaborative e-learners into a learning group. The other three independent variables i.e., Cognitive SRL Strategies, Metacognitive SRL Strategies and Resource Management SRL Strategies refer to the different types of strategies the e-learners apply in a collaborative selfregulated learning context. The values of these variables are the specific strategies applied under each of these three independent variables.

The intervening variable is Improved Learner Retention, which refers to increased numbers of e-learners who continue learning due to the various interventions implemented to reduce drop-outs. The dependent variable is the level of e-Learner Performance, which will be derived from individual and group outcomes (Fig. 4). The moderating variables are SRL Learner characteristics. Specifically, they are learner prior experience and group leadership. They moderate the relationships between the independent variables and the moderating variable. 


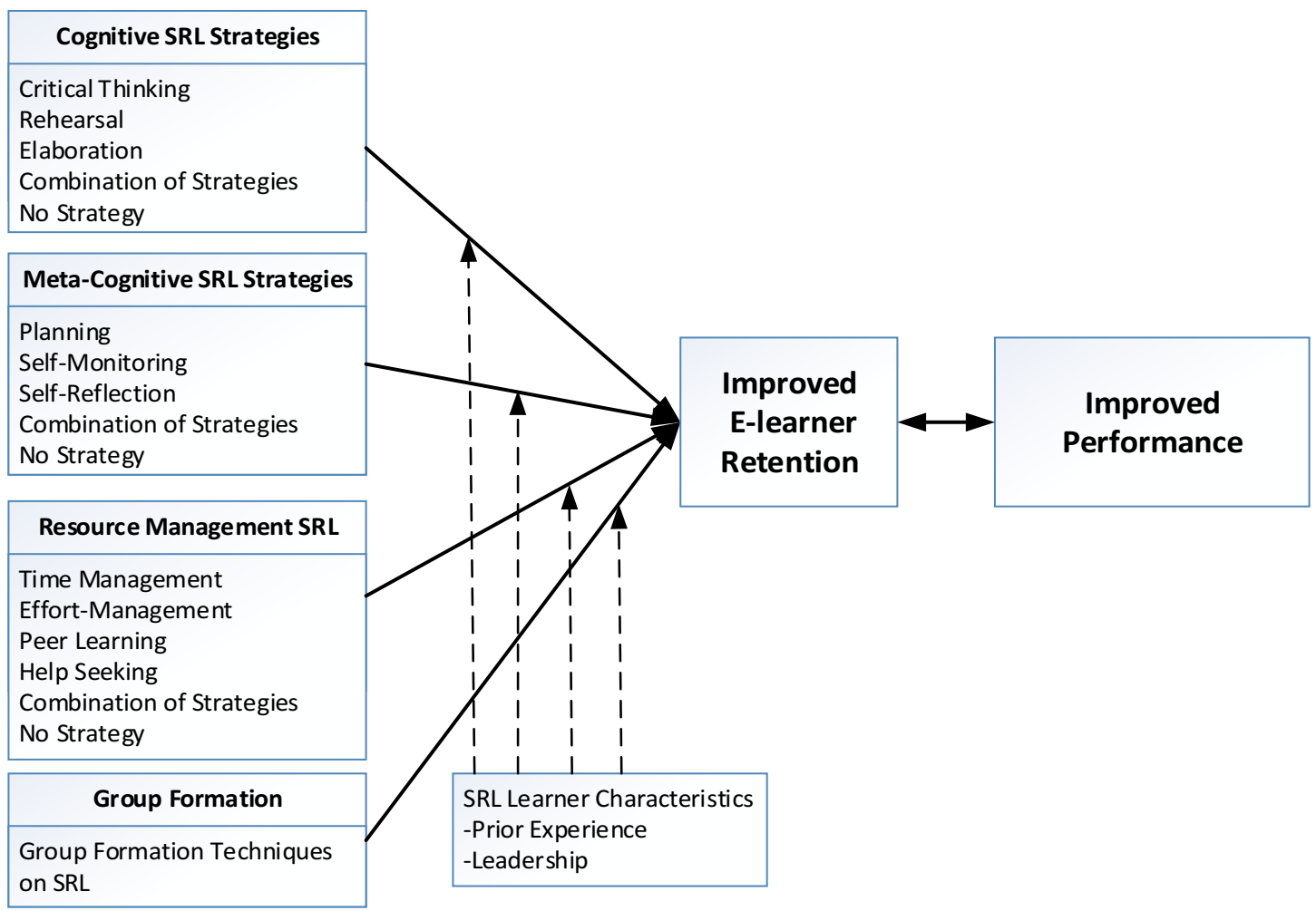

Fig. 4: Proposed collaborative SRL model

\section{Operationalization of Variables}

Literature has shown that collaborative e-learning finds its roots from social construction of knowledge. Thus, collaboration becomes an important aspect of learning for the constructivist pedagogy. The goal of collaborative e-learning is to create social interaction which will result to the acquisition or construction of new knowledge. A summary of the three SRL models, their characteristics and unique factors are discussed in Table 1. Operationalization of variables indicated in the proposed collaborative SRL model is shown in Table 2. The proposed relationships between variables and their meanings are outlined in Table 3.

\section{Benefits of the Proposed SRL Model}

The proposed collaborative SRL model will overcome the disadvantages of existing models in the following ways:

i. The model is suited for collaborative learning, by firstly focusing on individual learners' SRL, then on co-regulation and on shared-regulation of elearners ii. The model builds on strengths of the other SRL models, such as strong emphasis on self and external evaluation as a basis for self-reflection and self-regulation.

iii. The model is also detailed, just like the other two models. For example, it clearly defines the steps involved in self-regulation, for both individual learners and group learners.

iv. Most studies consider one or two SRL strategies to determine students' performance, mostly in traditional e-learning set-ups with a focus on individual regulation, though this has been established not to be effective for rating the different SRL strategies for collaborative elearners. This therefore necessitates the need for an SRL model with more collaborative strategies and approaches that focuses on reducing dropout rates of e-learners with improved performance

The model captures different SRL strategies and approaches which provide an effective way of differentiating collaborative e-learners. By incorporating the SRL theories in determining which learner characteristics to be used, the use of the SRL model proposed will aid effective e-learning. 
Table 1: SRL models comparison

\begin{tabular}{lll}
\hline Model & Characteristics & Unique SRL factors \\
\hline Zimmerman's & - The model is rather simplistic. It does not give a lot of details and & -Motivation \\
(2001) & simplifies actions into 3 phases. & Phases \\
& - Does not clearly show points of regulation in terms of support & -Forethought \\
& provision to learners. & -Performance \\
& - Defined for face-to-face learning. & -Control \\
& & -Self-reflection \\
Winne and Hadwin & - Is strong on evaluation as it has both self-evaluation and evaluation & -Conditions \\
s Model (1998) & by an external entity. Both evaluations can provide feedback & -Standards \\
& useful to spur the learner on an SRL environment. Has 4 phases. & Phases \\
& - It emphasizes on the motivation of the learner, which is a critical & -Task definition \\
& ingredient for successful SRL. & -Goal setting and planning \\
& - In each phase, the model provides clear details eg task conditions, & -Enacting study tactics \\
& cognitive conditions, Product phases, which provides opportunities for & -Meta-cognitively adapting studies \\
& providing further learning support to the learner in an SRL environment. & \\
Hadwin, Järvelä & - The model is defined for traditional learning environment. & \\
and Miller's & The model was designed for studies where collaborative learning takes & -Socially- shared regulation \\
Model (2011; & place, with each learner required to engage his/her own SRL strategies & Phases \\
$2013)$ & before contributing to group learning or building a shared reality. & -Planning \\
& The model has tasks, Conditions, Operations, Products, Evaluations and & -Negotiating \\
& Standards (COPES) just like in Winne and Hadwin's model. & -Task awareness \\
& It is defined for an e-learning context. & -Monitoring \\
& & -Control \\
& & -Strategic task engagement \\
& & -Regulating adaptation \\
\hline
\end{tabular}

Table 2: Operational definitions of variables

\begin{tabular}{|c|c|c|}
\hline $\begin{array}{l}\text { Model factor } \\
\text { (characteristic) }\end{array}$ & $\begin{array}{l}\text { Indicators to } \\
\text { be measured }\end{array}$ & $\begin{array}{l}\text { Meaning in this study } \\
\text { (measurement criteria) }\end{array}$ \\
\hline \multirow[t]{4}{*}{$\begin{array}{l}\text { Cognitive } \\
\text { SRL strategies }\end{array}$} & Critical thinking & $\begin{array}{l}\text { - The e-learner tries to decide if there is good supporting evidence when a theory, interpretation } \\
\text {, or conclusion is presented in class or in the readings, }\end{array}$ \\
\hline & Elaboration & -The e-learner tries to relate the material to what he already knows, when reading for a class \\
\hline & Rehearsal & $\begin{array}{l}\text { - The e-learner practices saying the material to himself or important facts over and over when } \\
\text { studying for a class or for a test. } \\
\text {-The e-learner asks himself questions to make sure he knows the material being studying }\end{array}$ \\
\hline & Organization & $\begin{array}{l}\text { - The e-learner outlines the material to help him organize his thoughts when studying the } \\
\text { readings for a course. } \\
\text { - The e-learner writes brief summaries of the main ideas from the readings and class notes, when } \\
\text { studying for a course. } \\
\text {-The e-learner makes simple charts, diagrams, or tables to help him organize course material }\end{array}$ \\
\hline Meta-cognitive & Goal setting & -The e-learner sets realistic deadlines for learning. \\
\hline \multirow[t]{2}{*}{ SRL strategies } & Self-monitoring & $\begin{array}{l}\text { - The e-learner asks himself questions to make sure he understands the material he has been } \\
\text { studying in class. } \\
\text { - The e-learner thinks about what he has learnt after finishing. }\end{array}$ \\
\hline & Strategic planning & - The e-learner organizes his study time to accomplish his goals to the best of his ability. \\
\hline Resource & effort regulation & -The e-learner works hard to do well in class even if he does not like the course \\
\hline management & Help seeking & - The e-learner asks for help mostly the instructor to clarify concepts he does not understand well \\
\hline SRL strategies & Time management & $\begin{array}{l}\text { - The e-learner tries to work with his classmates to complete the course assignments } \\
\text { - The e-learner makes good use of his study time for any course. } \\
\text { - The e-learner ensures that he keeps up with weekly readings and assignments }\end{array}$ \\
\hline Group formation & Without Intelligence & -Using one of the following: random; self; placement by instructor \\
\hline techniques on SRL & Intelligent SRL grouping & -Using a Machine Learning Algorithm \\
\hline \multirow[t]{2}{*}{$\begin{array}{l}\text { E-learner } \\
\text { characteristics }\end{array}$} & Prior experience & $\begin{array}{l}\text {-Whether the e-learner has previous experience using an LMS } \\
\text {-Whether the e-learner has prior experience using collaborative learning strategies and tools }\end{array}$ \\
\hline & Leadership & $\begin{array}{l}\text { - The e-learner expect to do well when compared with other students in his class. } \\
\text { - The e-learner's SRL strategies are excellent compared with others in the class } \\
\text { - The e-learner thinks he knows a great deal about the subject compared with other students } \\
\text { in the class }\end{array}$ \\
\hline Learner retention & & -The tendency of the e-learner to continue learning (not to drop out) \\
\hline Learner performance & & The standardized average score an e-learner obtains at the end of a course. \\
\hline
\end{tabular}


Table 3: Proposed Relationships between variables

\begin{tabular}{|c|c|}
\hline Proposed relationship & Meaning in this study \\
\hline $\begin{array}{l}\text { Cognitive SRL strategies and } \\
\text { learner retention }\end{array}$ & $\begin{array}{l}\text {-When cognitive strategies are used and are encouraged through building support in an } \\
\text { LMS, Learner Retention improves. }\end{array}$ \\
\hline $\begin{array}{l}\text { Metacognitive SRL strategies } \\
\text { and learner retention }\end{array}$ & -When metacognitive strategies are applied and they work, Learner Retention improves. \\
\hline $\begin{array}{l}\text { Resource management SRL } \\
\text { strategies and learner retention }\end{array}$ & $\begin{array}{l}\text { - There is a significant and positive relationship between Resource support in an } \\
\text { management SRL strategies and learner Retention }\end{array}$ \\
\hline $\begin{array}{l}\text { Group formation techniques } \\
\text { on SRL and learner performance }\end{array}$ & - The technique used for group formation has an effect on Learner Retention \\
\hline $\begin{array}{l}\text { Prior experience of the e-learner } \\
\text { and learner retention }\end{array}$ & $\begin{array}{l}\text {-A Greater Prior Experience of the e-Learner with SRL strategies and tools or LMS will } \\
\text { improve Learner Retention }\end{array}$ \\
\hline $\begin{array}{l}\text { Leadership e-learner characteristic } \\
\text { and learner performance }\end{array}$ & $\begin{array}{l}\text {-A higher presence of Leadership traits in an e-Learner will have a higher significant } \\
\text { positive effect on Learner Retention }\end{array}$ \\
\hline $\begin{array}{l}\text { Learner retention and learner } \\
\text { performance }\end{array}$ & -An increase in Learner Retention improves Learner Performance \\
\hline
\end{tabular}

\section{Methodology}

\section{Research Design}

The study will use a pragmatism research philosophy, where a cross-sectional design using descriptive survey will be used to investigate the collaboration level of learners with peers and in group work. Supports will be developed and integrated within an LMS, for the various strategies applied by learners in this context. The descriptive survey will be adopted given its possibility to examine a situation the way it is and provide quantitative information, summarized through statistical analyses (Engelhart, 1972).

\section{Sample and Sampling Procedures}

Purposive sampling will be adopted to select three public universities, which have adopted the use of collaborative e-learning tools in their e-learning in Kenya. Purposive sampling will also be used to select learners engaged in online collaborative activities using varied SRL strategies.

\section{Participants}

With the help of instructors and course facilitators, 300 students will be identified within the three public universities. These will be students pursuing at least one course or a module online on the university elearning platform. The sampled students will be informed by their instructors of the purpose of the study and responding to the questionnaire items will be on a voluntary basis.

\section{Data Analysis}

This survey will be conducted by administering questionnaires using Lime survey web-based tool. This approach is preferred because it will enable a faster collection of responses and the ease of exporting the data to be analyzed.

\section{Research Instruments Used}

Self-regulated learning strategies will be measured using the Motivated Strategies for Learning Questionnaire (MSLQ) (Pintrich et al., 1991). It is a self-report instrument designed to assess college students' motivational orientations and their use of different learning strategies for a college course (Pintrich et al., 1991). The learning strategy section of the MSLQ includes 31 items regarding students' use of different cognitive and meta cognitive strategies. In addition, the learning strategies section includes 19 items concerning student management of different resources. Students rate themselves on a Likert scale.

\section{Conclusion and Recommendation}

This study is set to establish the effect of SRL theories, strategies and approaches on collaborative elearning systems and to develop an SRL model based on these factors. The study is based on the social cognitive theory. The most modelled SRL strategy is metacognition.

The authors are currently focusing on the development of an intelligent supports for SRL as collaborative elearning plugins based on the proposed SRL model. The proposed SRL model will be used on an asynchronous elearning environment in Kenyan Universities.

\section{Acknowledgement}

This research was made possible by the support provided by the University of Nairobi through journal subscriptions, need-based acquisition and a favourable research environment. We also acknowledge the universities in which the pre-study was carried out.

\section{Author's Contributions}

All authors equally contributed in this work. 


\section{Ethics}

This article is original and contains unpublished material. Both the corresponding author and the coauthor confirm that they have read and approved the manuscript and that no ethical issues are involved.

The authors declare that they have no competing interests.

\section{References}

Alvi, E., Z. Iqbal, F. Masood and T. Batool, 2016. A qualitative account of the nature and use of SelfRegulated Learning (SRL) strategies employed by university students. Australian J. Teacher Educat.

Artino, A.R. and K.D. Jones, 2012. Exploring the complex relations between achievement emotions and self-regulated learning behaviors in online learning. Int. Higher Educat., 15: 170-175. DOI: 10.1016/j.iheduc.2012.01.006

Bandura, A., 1986. Social Foundations of Thought and Action. 1st Edn., Prentice Hall. pp: 617.

Bembenutty, H., M.C. White and M.K. DiBenedetto, 2016. Applying Social Cognitive Theory in the Development of Self-Regulated Competencies Throughout K-12 Grades. In: Psychosocial Skills and School Systems in the 21st Century, Lipnevich A., F. Preckel and R. Roberts (Eds.), Springer Series on Human Exceptionality, ISBN-13: 978-3-319-28604-4, pp: 215-239.

ChanLin, L.J., 2012. Learning strategies in websupported collaborative project. Innovat. Educat. Teaching Int., 49: 319-331. DOI: $10.1080 / 14703297.2012 .703016$

Cho, M. and D. Shen, 2013. Self-regulation in online learning. Distance Educat., 34: 290-301. DOI: $10.1080 / 01587919.2013 .835770$

Dweck, C.S. and A. Master, 2008. Self-Theories Motivate Self-Regulated Learning. In: Motivation and Self-Regulated Learning: Theory, Research and Applications, Schunk, D.H. and B.J. Zimmerman (Eds.), Lawrence Erlbaum Associates Publishers. Mahwah, NJ, US, pp: 31-51.

Effeney, G., A. Carroll and N. Bahr, 2013. Selfregulated learning: Key strategies and their sources in a sample of adolescent males. Australian J. Educat. Dev. Psychol., 13: 58-74.

Engelhart, M.D., 1972. Methods of educational research. Rand McNally. Chicago.

Greene, J.A., D.C. Moos and R. Azevedo, 2011. Selfregulation of learning with computer-based learning environments. New Direct. Teach. Learn., 126: 107-115. DOI: 10.1002/tl.449
Greenland, S. and C. Moore, 2014. Patterns of online student enrolment and attrition in Australian open access online education: A preliminary case study. Open Praxis Int. Council Open Distance Educat., 6: 45-54.

DOI: 10.5944/openpraxis.6.1.95

Hadullo, K., R. Oboko and E. Omwenga, 2018. Factors affecting asynchronous e-learning quality in developing countries university settings. Int. J. Educat. Dev. Using Inform. Commun. Technol., 14: 152-163.

Hadwin, A.F., S. Järvelä and M. Miller, 2011. SelfRegulated, Co-Regulated and Socially Shared Regulation of Learning. In: Educational Psychology Handbook Series Handbook of Self-Regulation of Learning and Performance, Zimmerman, B.J. and D.H. Schunk (Eds.), Routledge/Taylor and Francis Group, New York, NY, US, pp: 65-84.

Järvelä, S., P.A. Kirschner, A.F. Hadwin, H. Järvenoja and J. Malmberg et al., 2016. Socially shared regulation of learning in CSCL: Understanding and prompting individual-and group-level shared regulatory activities. Int. J. Comput. Supported Collaborative Learn., 11: 263-280.

Järvelä, S. and A.F. Hadwin, 2013. New frontiers: regulating learning in CSCL. Educ. Psychol., 48: 25-39. DOI: 10.1080/00461520.2012.748006

Johnson, L., S. Adams Becker, M. Cummins, V. Estrada and A. Freeman et al., 2016. NMC horizon report: 2016 higher education edition. The New Media Consortium and EDUCAUSE Learning Initiative, Austin.

Kashorda, M. and T. Waema, 2014. E-Readiness survey of Kenyan Universities (2013) report, Kenya Education Network, Nairobi.

Klingsieck, K.B. and S. Fries, 2012. Procrastination: Development and validation of a German short scale of the general procrastination scale (lay, 1986). Diagnosticas, 58: 182-193.

DOI: $10.1026 / 0012-1924 / \mathrm{a} 000060$

Lee, Y. and J. Choi, 2011. A review of online course dropout research: Implications for practice and future research. Educat. Technol. Res. Dev., 59: 593-618. DOI: 10.1007/s11423-010-9177-y

Lock, J., S.E. Eaton and E. Kessy, 2017. Fostering selfregulation in online learning in k-12 education. Northwest J. Teacher Educat.

Lodge, J.M., E. Panadero, J. Broadbent and P.G. De Barba, 2018. Supporting Self-Regulated Learning with Learning Analytics. In: Learning Analytics in the Classroom, Lodge, J., J.C. Horvath and L. Corrin (Eds.). 
Maina, E., M.P.W. Waiganjo and R.O. Oboko, 2017. Students' perceived challenges in an online collaborative learning environment: A case of higher learning institutions in Nairobi, Kenya. Int. Rev. Res. Open Distance Learn.

Makokha, G. and D. Mutisya, 2016. Status of e-learning in Public Universities in Kenya. Int. Rev. Res. Open Distributed Learn, 19: 139-160.

Meyer, D.K. and J.C. Turner, 2002. Using instructional discourse analysis to study the scaffolding of student self-regulation. Educat. Psychol., 37: 17-25. DOI: $10.1207 /$ S15326985EP3701_3

Michinov, N., S. Bronot, O. Bohec, J. Juhel and M. Delaval, 2011. Procrastination, participation and performance in online learning environments. Comput. Educat.

Muuro, E.M., R. Oboko and P.W. Waiganjo, 2016. Evaluation of intelligent grouping based on learners' collaboration competence level in online collaborative learning environment. Int. Rev. Res. Open Distributed Learn, 17: 40-64.

DOI: 10.19173/irrodl.v17i2.2066

Oboko, R.O., 2012. Adaptive learning and metacognitive regulation support for ill-structured problem solving processes in web-based learning.

Panadero, E. and S. Järvelä, 2015. Socially shared regulation of learning: A review. Eur. Psychol., 20: 190-203. DOI: 10.1027/1016-9040/a000226

Panadero, E., 2017. A review of self-regulated learning: Six models and four directions for research. Front Psychol., 8: 422-422.

DOI: $10.3389 /$ fpsyg.2017.00422

Perry, N. and A. Rahim, 2011. Studying Self-Regulated Learning in Classrooms. In: Handbook of SelfRegulation of Learning and Performance, Zimmerman B.J. and D.H. Schunk (Eds.), Routledge, New York, pp: 122-136.

Pintrich, P., D. Smith, T. García and W. McKeachie, 1991. A manual for the use of the Motivated Strategies for Learning Questionnaire (MSLQ), University of Michigan, Ann Arbor, MI.

Puzziferro, M., 2008. Online technologies self-efficacy and self-regulated learning as predictors of final grade and satisfaction in college-level online courses. Am. J. Distance Educat., 22: 72-89.

Richardson, M.J., C. Abraham and R. Bond, 2012. Psychological correlates of university students' academic performance: A systematic review and meta-analysis. Psychol. Bull., 138: 353-387. DOI: $10.1037 / \mathrm{a} 0026838$

Sanja, I.B., 2015. Assessing students' perception of elearning in blended environment: An Experimental Study. Proc. Soc. Behav. Sci., 191: 323-329.

DOI: $10.1016 /$ j.sbspro.2015.04.393
Siddiqui, A.T. and M. Masud, 2012. An e-learning system for quality education. Int. J. Comput. Sci.

Ssekakubo, G., H. Suleman and G. Marsden, 2011. Issues of adoption: Have e-learning management systems fulfilled their potential in developing countries? SAICSIT.

Tarus, J.K., D. Gichoya and A. Muumbo, 2015. Challenges of implementing e-learning in Kenya: A Case of Kenyan Public Universities. Int. Rev. Res. Open Distributed Learn.

Wandler, J. and W. Imbriale, 2017. Promoting undergraduate student self-regulation in online learning environments. Online Learn., 21: 2-2. DOI: $10.24059 /$ olj.v21i2.881

Wang, C.H., D.M. Shannon and M.E. Ross, 2013. Students' characteristics, self-regulated learning, technology self-efficacy and course outcomes in online learning. Distance Educat., 34: 302-323. DOI: $10.1080 / 01587919.2013 .835779$

Wang, S.L. and P.Y. Wu, 2008. The role of feedback and self-efficacy on web-based learning: The social cognitive perspective. Comput. Educat., 51: 1589-1598. DOI: 10.1016/j.compedu.2008.03.004

Wentling, T., C. Waight, J. Gallager, J. La Fleur and C. Wang et al., 2000. E-learning: A review of literature. University of Illinois, Urbana-Champaign, IL.

Winne, P. H. and A.F. Hadwin, 1998. Studying as SelfRegulated Engagement in Learning. In: Metacognition in Educational Theory and Practice, Hacker, D., J. Dunlosky and A. Graesser (Eds.), Erlbaum, Hillsdale, NJ, pp: 277-304.

Wong, J., M. Baars, D. Davis, T. Van-Der-Zee and G. Houben et al., 2019. Supporting self-regulated learning in online learning environments and MOOCs: A systematic review. Int. J. HumanComput. Interact., 35: 356-373. DOI: $10.1080 / 10447318.2018 .1543084$

Zimmerman, B.J. and D.H. Schunk, 2011. Handbook of Self-Regulation of Learning and Performance. 1st Edn., Routledge, ISBN-10: 0415871123, pp: 500.

Zimmerman, B.J., 2000. Attainment of SelfRegulation: A Social Cognitive Perspective. In: Handbook of Self-Regulation, Boekaerssts, M., P.R. Pintrich and M. Zeidner (Eds.), Academic Press, San Diego, pp: 13-39.

Zimmerman, B.J., 2002. Becoming a self-regulated learner: An overview. Theory Practice, 41: 64-70. DOI: $10.1207 / \mathrm{s} 15430421$ tip4102_2 